\title{
THE CULTIVATION OF TISSUES IN EXTRANEOUS MEDIA AS A METHOD OF MORPHO- GENETIC STUDY ${ }^{1}$
}

\author{
ROSS G. HARRISON \\ Yale University, New Haven, Conn.
}

During the past year we have heard much of the subject of this discussion, and the fact that tissues of the higher animals may be cultivated outside the body has been heralded in the newspapers and magazines as a notable, if not a revolutionary, scientific discovery. When we pause to consider this claim in the light of what has actually been accomplished, we find that there is danger not only of confusing in our minds several quite different things, but also that in our enthusiasm for the novelty of the method we may forget the fundamental problems to the solution of which it may be able to contribute-if used critically.

We are taught in every text book of general biology and of physiology that the organism is made up of constituent cells, which, while interdependent in the body of the organism, nevertheless have a certain autonomy. In the usual physiological discussion of death, for instance, we find the distinction drawn between the death of the organism as a whole and the death of its constituent parts. It has been known for a considerable time, that even the heart of warm blooded animals may be isolated from the body and with proper nourishment may continue to beat for many hours; more recently some very remarkable cases of the survival of organs have been reported by Carrel, ${ }^{2}$ who has demonstrated that the vital functions of isolated organs may be kept in abeyance for days, to begin again without impairment when the organs are reëngrafted into the body of an animal.

${ }^{1}$ Read before the American Association of Anatomists, December 27, 1911 at Princeton, N. J. in open ing the Symposium on "Tissue Culture."

${ }^{2}$ Jour. Exp. Med., vol. 9, 1907; ibid, vol. 12, 1910. 
While the experiments made with fragments of tissue cultivated in vitro show that cells which are entirely isolated or are left together in small aggregates have the faculty of survival in common with whole organs, it is not this, as such, nor is it the fact that we can cultivate animal cells in extraneous media just as we can grow microörganisms, that would entitle the experiments to more than passing attention. Their importance rests, rather, upon the circumstance that they afford a means not only of observing the activities of cells when freed from the entanglements of the organism, but also of studying the conditions which influence these activities-activities which constitute morphogenetic as well as maintenance functions of cells and tissues.

As far as questions of morphogenesis are concerned, our method of investigation is but the logical outcome of the experimental embryological method of Roux, Driesch and Born, in which the isolation of embryonic parts is employed to test their function in the formation of the organism. It was a definite problem of this kind, concerning the development of the nervous system, that led me to carry the method to its extreme after the observation of normal preserved embryos and other methods of experiment had gone as far as they could and had failed to solve the problem. In order to determine whether the neuroblasts are in themselves competent to form nerve fibers, it became necessary to remove them from all sources of contamination obtaining within the body. The ubiquity of Hensen's protoplasmic bridges or Held's plasmodesms, was always liable to vitiate observations upon the growth of nerve fibers within the embryo, so that the only effective way to proceed in this particular case was to place embryonic nervous tissue in some compatible foreign medium, where it would have the chance to grow independently of its usual surroundings.

The logical process involved in an experiment of this kind affords nothing unusual. Two factors, the protoplasmic activity of embryonic nerve cells and the peripheral protoplasmic bridges, were suspected of giving rise to nerve fibers. The experiments in question eliminated the second of these factors, previous experiments having eliminated the first, and the results showed beyond 
question that nerve fibers are formed only when nerve cells are present, and that they are formed as well in the absence as in the presence of the protoplasmic bridges.

There are many who would deny to this type of experiment validity in elucidating the phenomena of normal development, maintaining that the experimental conditions are too radically different from the normal to be of value in interpreting the latter. Objections of this kind are not without ground, and they have not been disregarded by those who have employed the experimental method. They have been precisely stated by Roux in his "Einleitung zum Archiv für Entwickelungsmechanik,", where it is pointed out that experiments upon living organisms, particularly in cases of mutilations or of disturbance in the arrangement of parts are likely to call forth secondary regulatory processes, and it is the difficulty in distinguishing between these and the mechanisms of the direct or normal development that constitutes the danger in drawing conclusions regarding the latter from experiments such as those just described.

What, then, are the criteria by which we may judge whether experiments upon living organisms may be used in interpreting normal processes of development? In attempting to answer this question we are confronted with a more fundamental one and are forced to ask ourselves if there is actually anything peculiar in this regard in experiments upon developing organisms beyond the fact of the complexity of the material.

All 'normal' vital processes are, as we observe them, bound up with complex things which we call organisms. As soon as we institute any disturbance of the organism, whether it be by removing part of it, by stimulating one of its nerves electrically, or, for the purpose of studying its behavior, by placing it in an environment which it would not find in nature, we are bringing about 'abnormal' conditions and may be calling forth all kinds of regulatory responses. We cannot, therefore, be sure that just the same factors combine to produce the result in the 'normal' organism as in the one experimented upon. In other words,

${ }^{3}$ Arch. f. Entwickelungsmech., Bd. 1, 1894, pp. 19-20. 
the argument against the experimental method based upon the ground that abnormal conditions arise, is quite as cogent against the simplest physiological experiment as against the most radical one in morphogenesis. And further, the same argument might be urged even against physical and chemical operations, on the ground that the exclusion of one factor released some entirely different factor which did not act in its presence. In other words, it seems clear that, as far as the logic of the experimental method is concerned, the occurrence of regulatory processes in organisms affords but a particular illustration of those circumstances known as 'Plurality of Causes,' and 'Intermixture of Effects,' which render experimental work in any field full of difficulties and pitfalls. ${ }^{4}$

Neither the physicist nor the chemist allow themselves, however, to be deterred from experimenting by difficulties of this kind. They do not confine themselves to the contemplation of the 'normal,' i.e., to events as they occur in nature, but they endeavor by processes of analysis to resolve natural phenomena into more elemental factors, from which, for purposes of verification, phenomena like the original may be recomposed or be represented more or less perfectly by some kind of model, according to the completeness of the knowledge gained by the analysis.

Why, then, should we, in morphology, be still so dominated by the conception of the object as it occurs in nature, the organism as a whole, which to many seems to be a sort of fetish not to be touched lest it show its displeasure by leading the offender astray? There is no real ground for maintaining this attitude. On the contrary we should endeavor to extend our experimental analysis wherever possible, recognizing that through study of the abnormal, which consists merely of those combinations of conditions and effects that do not ordinarily occur in nature, we have the best means of reaching an understanding of the normal, and that it is necessary to investigate the properties of the constituent parts of organisms before we can hope to understand them in their entirety. Because of our limited knowledge we are for the present setting ourselves an impossible task if we expect to determine with

${ }^{4}$ ef. J. S. Mill, Logic, 8th Ed., New York, p. 311. 
certainty by means of a few experiments exactly the combination of factors involved in the normal ontogeny of any particular structure. In fact we can never 'explain' the processes of normal development with more than a certain degree of probability, until we succeed in synthesizing organisms ${ }^{5}$ from simple known constituents or construct working models that show all of the essential activities of organisms-achievements from which we still are very far removed. Syntheses may possibly be made, however, at different stages of the analysis with components of greater or lesser complexity. Thus it may be possible to extend the remarkable experiments of $\mathrm{H}$. V. Wilson, ${ }^{6}$ who has succeeded in getting the dissociated cells of sponges and hydroids to reassemble and develop into normal organisms, so that similar methods may be applied to verify the results of analyses made by the methods of cultivation of cells and tissues outside the body.

While the foregoing considerations may have succeeded in establishing the point that the immediate object of experimental morphogenesis should be analysis, and that the 'explanation' of normal development will only come with any degree of certainty in a roundabout way, after the analysis has been made, they have not given a satisfactory answer to the query made in the beginning "What are the criteria by which we may judge whether experiments upon living organisms may be used directly in interpreting normal processes of development?" In fact we have almost stated that there are no criteria by which we may be absolutely certain that the same combinations of circumstances are operative in producing an effect within the untouched organism and in the one experimented upon. We can, however, extend the results of experiments directly to cover the normal processes of development provided we are reasonably sure that the circumstances of plurality of causes and intermixture of effects have been excluded, or at least that regulatory processes are not taking place. This can best be accomplished by careful comparison of what occurs in experiments with what can be observed in the normal developing organism. What we then find in the experiments

${ }^{5}$ cf. Mill, op. cit., p. 328.

${ }^{6}$ Jour. Exp. Zoöl., vol. 5, 1907; ibid, vol. 11, 1911. 
under known conditions may be used to assign, with probability, definite causal connections to similar sequences of events in the organism. Such a process of reasoning is most certain in cases of self differentiation.

Satisfied that experiments upon living organisms are not by any means misleading even when abnormalities result, and that they differ from other experiments only in the degree of complexity of the conditions to be analyzed, we may now consider the purpose and the advantages of the method of tissue culture itself. In the first place, it enables us to take an essential step in the analysis of the phenomena of development into their elements in that it makes it possible to study the properties of individual cells and small masses of homogeneous tissue of almost any kind at any stage of development, whereas heretofore in our studies upon the morphogenetic properties of living cells we have been limited to the unicellular organisms, the germ cells and the blastomeres of the segmenting egg. In particular, the method of culture in small glass chambers renders amenable to direct observation a wide range of phenomena that otherwise could only be inferred by putting together observations upon preserved tissue; also it is possible by the method to subject the isolated cells and tissues to almost any changes of conditions, whereby the effect of the external medium and the interaction between cells of various kinds may be studied; or the self differentiation of any tissue may be tested with a degree of precision heretofore unattained.

The processes of development may accordingly be studied by the method with different immediate ends in view. The object may be to find out simply whether a certain tissue arises from one rudiment in the embryo or another, as was the case with the first experiments of my own upon the nerve fiber. Experiments of this class are dependent for their accuracy, as pointed out previously, upon a high degree of self differentiation in the tissues studied. On the other hand, the purpose may be to study the factors, both internal and external, which influence various processes of development such as growth, movement and tissue differentiation. In experiments of this kind all that we can expect to do is to imitate by means of known factors the conditions found 
in the embryonic body, and by varying them in a known way to establish definite relations between each set of conditions and its result. By comparing the phenomena with those observable in the embryo, we may with a varying degree of probability draw conclusions regarding the causal nexus of the factors acting within the normal body. In carrying over the conclusions drawn from such experiments to the phenomena of normal occurrence we are subject, however, to all the hazards which attend experimental work in any field, and these are in proportion to the complexity of the conditions to be analyzed. That the hazard may be lessened to a minimum we must vary our experiments as much as possible in essentials, and above all must never lose sight of what can be observed in the normal organism.

In making my experiments on the development of the nerve fiber, the point that concerned me most at the outset was to establish as securely as possible the thesis that the processes of development witnessed in the artificial cultures were the counterpart of what took place within the embryo, for failing in this, the method would have been of no value for my immediate purpose. Accordingly, after finding a medium in which the embryonic tissues would live for a long period, the first thing to do was to study the activities of as many different tissues as possible. ${ }^{7}$ In this preliminary work it was found that nearly all embryonic cells exhibit marked motility, which, as detailed observation show, is due to the movement of the hyaline ectoplasm accumulated at the borders and especially at the angles of the cells. Fine filamentous pseudopodia are there formed, and through their activity the cells change shape or move from place to place. The character and rapidity of the motion is not the same in all kinds of cells. The most independent in their movements are elements from the neural tube and the axial mesoderm, which often form a mesenchyme-like network, and the former also give rise to the long filamentous processes identical with the primitive nerve fibers of the embryo. Epidermal cells remain in sheets and frequently produce along their border a hyaline fringe of ectoplasm with pseudopodia simi-

${ }^{7}$ cf. Harrison, Proc. Soc. Exp. Biol. and Med., vol. 3, 1907; Jour. Exp. Zoöl., vol. 9, 1910. 
lar to that formed in the healing of wounds. In contrast to this behavior, cells of the notochord and yolk-laden endoderm remain inert. These activities of course bear comparison with the processes of mesenchyme wandering, the outgrowth of the ganglion crest, the formation of nerve fibers, etc., in the body of the embryo. A still closer parallel exists between embryonic and extraembyronic processes of tissue differentiation, for we find that each kind of cell isolated in the culture media undergoes characteristic histogenetic changes. This is very striking in the case of striated muscle, pigment cells, and ectodermal structures such as the cuticular border and cilia, not, at present, to mention nerve fibers. These studies reveal, therefore, a high degree of self differentiation of the cells of the frog and chick embryo at the stage under consideration, and for that reason the method may be safely used for the determination of the source of tissue elements in the normal embryo. By pushing our studies back into the earlier stages of development, in all probability we shall be able to gain much further information with regard to the exact period at which potential differentiation (not immediately perceptible) takes place in each tissue.

Having established the validity of our method, the application of it to the central problem of nerve development became a matter of no difficulty. To decide which particular cells gave rise to the actual nerve fiber it was necessary merely to isolate the suspected ones, i.e., the embryonic nerve cells. The result clearly showed that the cells of the ganglionic centers, either the medullary cord or the cranial ganglia, alone produce the nerve fibers, in first instance by a process of movement, whereby the fiber is drawn out toa thread, and this is followed by a process of chemical differentiation within the protoplasmic filament, whereby neurofibrillae are laid down. There can thus be no doubt but that the substance of the axone is derived from the ganglion cell alone in the manner first described by His.

The experimental analysis of the factors which influence the movement of cells, as regards both intensity and direction, will befound to have a direct bearing upon the interpretation of normal 
ontogenetic processes. ${ }^{8}$ The study of the general conditions under which movement is possible must be carried on with reference to conditions of light, temperature and chemical constitution of the medium, including oxygen supply. In this way we shall be able to find not only the limits within which the locomotor activities may take place but also the factors which accelerate or retard them. The same problem obtains in respect to the phenomena of cell multiplication and growth, but unfortunately we here have a difficulty in distinguishing between mere movement (wandering of cells) and actual growth due to proliferation. Agood beginning in this field has been made by Carrel and Burrows, ${ }^{9}$ by Ruth ${ }^{10}$ and by M. R. and W. H. Lewis, ${ }^{11}$ and, especially for the phenomena of tumor growth, by Lambert and Hanes. ${ }^{12}$

There is another factor in the environment which has to do neither with external forces nor with the chemical composition of the medium, but yet is of great importance in its influence upon the movement of cells. I refer to the presence of some form of solid support upon which the cells may creep. The necessity of some such support seemed probable from the results of my first experiments with nervous tissue.

Experiments which I carried on during the past summer have proved the correctness of the supposition as far as the various kinds of cells in the embryos of the frog and the chick are concerned, thus affording a striking example of cellular stereotropism, a form of reaction considered by L. Loeb, ${ }^{13}$ from his numerous experiments, to play an important part in the regenerative growth of epithelium and in the proliferation of carcinomatous tissue. The purpose was accomplished by varying the character of the solid surface offered, as well as that of the fluid media, with

${ }^{8} \mathrm{cf}$. W. Roux's studies on cytotropism and kindred phenomena, in which methods somewhat like the present ones were used. Arch. f. Entwickelungsmech., Bd. 1, 1894; ibid, Bd. 3, 1896.

${ }^{9}$ Jour. Exp. Med., vol. 13, 1911.

10 Jour. Exp. Med., vol. 13, 1911.

11 Anat. Rec., vol. 5, 1911.

12 Jour. Exp. Med., vol. 13, 1911; ibid, vol. 14, 1911; Jour. Am. Med. Ass., vol. 56,1911 .

${ }_{13}$ Arch. f. Entwickelungsmech., Bd. 6, 1897; Bd. 13, 1902. 
the result of showing that movement would take place upon various solids in media of different constitution, but not in the same media when the cells were deprived of solid support.

The early observations which had led me to suspect the importance of support were merely that specimens cultivated in lymph which clotted well almost always showed movement, while in those in which the lymph failed to clot this was never the case. The first experiments directed to the definite solution of this problem were made upon tissues from early frog embryos. ${ }^{14}$ Clotting media were dispensed with, solid support was offered in the form of spider web upon which the tissues were mounted in small drops of fluid, such as defibrinated serum and inorganic salt solutions, which were varied in the different experiments; controls were made in which the tissue was suspended in hanging drops of the same media but without support. In the preparations in which the tissue is supported on a film of spider web much active movement takes place. Strands of cells are found to invest the web fibers, just as in the embryo they form the sheath to nerves, tendons and blood vessels..$^{15}$ Single cells adapt themselves to the web, assuming bipolar form on single fibers, tri- or quadripolar form when two fibers cross one another. Change of form and locomotion may be readily observed, but only when the cells are in contact with the solid support. On the other hand, the hanging drop preparations show no activities of this kind, the tissue partly disintegrating into cells which remain rounded and inactive, though differentiation within small masses of cells often takes place, especially in muscle. Apparent exceptions to the rule proved to be due to the contact of the tissue with the coverglass, upon which it was found that cells would migrate. The last named observation led to a further and more extensive set of experiments upon tissues of the chick embryo, with further variation in the solid support. In each group of experiments four different kinds of preparations were made, in which the same

${ }^{14} \mathrm{ef}$. Harrison, Science, vol. 34, 1911. Simultaneously with this Carrel and Burrows showed that cells would cling and grow upon fine silk textiles and cotton fibers. Jour. Exp. Med. vol. 14, 1911.

${ }^{15}$ cf. J. Loeb. Jour. Morph., vol. 8, 1893; Biol. Lect., Woods Hole (1897-8), 1899. 
tissue and the same fluid medium were used but which differed from each other in the presence, or absence, or in the character, of the solid support. The specimens were mounted in the following ways:

1. In clotted hen plasma.

2. In defibrinated plasma but supported by spider web.

3. In a hanging drop of defibrinated plasma so small that the tissue remained in contact with the cover slip.

4. In a large hanging drop without contact with the cover slip or any other solid body.

In the preparations of each of the first three classes characteristic movement of cells of a number of different kinds of tissue took place, while in the fourth the tissue remained inert, except, in several cases for a slight movement upon the surface film. The experiments were varied both as to the tissue used and as to fluid medium, salt solutions being used in some cases, but the results were essentially the same as in the series with serum. The behavior of the cells with reference to the surface of the cover slip and spider web shows not only that the surface of a solid is a necessary condition but also that when the latter has a specific linear arrangement, as in the spider web, it has an action in influencing the direction of the movement, as well as upon the form and arrangement of the cells.

These facts are significant for our interpretations of the cell movements which take place in the embryo, especially those which occur in the breaking down of the mesenchyme, in the formation of the spinal and sympathetic ganglia, and in the laying down of the peripheral nerve fibers. The embryo at this stage consists largely of compact masses of cells with small spaces between. It is in these spaces that the embryonic connective tissue, nerve cells and nerve fibers move. The latter may be seen, as shown beautifully in Held's figures, clambering along the inner surface of the muscle plates or the under surface of the epidermis. The plasmic bridges or epithelial connective tissue of Held may also play an important function here, not, however, in being transformed into nerve fibers, a process the occurrence of which is dis- 
proved by the experiments, but in forming a support or lattice along which the growing nerve fibers may entwine themselves.

By means of a modification of Pfeffer's method ${ }^{16}$ beginnings have been made in the study of the action of chemical substances upon the direction of movement of the cells. Very minute capillary tubes in which the opening is drawn out to a still more minute point are first filled with some fluid the activity of which it is desired to test and are then implanted in the culture drop with the opening of the tube not far from the growing tissue. It is expected that in this way the movement or growth of cells may be directed either toward or away from the substance issuing from the mouth of the tube. The results are as yet too scattered and too inconstant to warrant any statement regarding them. One serious difficulty seems to be the slowness of the reaction of the cells. Whereas protozoa and swarm spores move very rapidly and respond quickly to the chemical environment, in the implanted tissue there is a long latent period before any movement begins, and it is very slow when it does come, so that much diffusion occurs from the mouth of the tube before any visible change in the preparation takes place.

By appropriate modifications of methods which have already been applied we may hope also to observe the response of various embryonic cells to heat, light and electric current. Again, by using media with solid support, such as fibrin, it may also be possible to test further the motor reactions of cells to one another, which have been described by Roux as taking place in fluid media. ${ }^{17}$

In the way first indicated we may hope to gain a very complete knowledge of the movements of embryonic cells, which are of great importance in morphogenesis. As a check to our notions thus gained, we are fortunate in having such natural objects as the fin fold of various vertebrate embryos in which similar activities may be observed in the living whole organism..$^{18}$

${ }^{16}$ Ber. d. deutsch. Bot. Gesellsch., Bd. 1, 1883.

17 Arch. f. Entwickelungsmech., Bd. 1, 1894.

${ }^{18}$ ef. Kölliker: Ann. d. Sci. Nat., 3 S., T. 6, 1846; Harrison: Sitz. Ber. d. niederrh. Ges. f. Nat. u. Heilkunde. Bonn, 1904; id., Anat. Rec., vol. 1, 1908; E. R. Clark: Anat. Rec., vol. 3, 1909; J. Ferguson: Biol. Bull., vol. 21, 1911. 
The study of differentiation may be approached in somewhat similar ways though it will undoubtedly offer greater difficulties. The method is adapted par excellence to the determination of the limits of self differentiation, though it is not unreasonable to expect that we may ultimately find out much regarding the effect of the chemical content of the medium and other environmental factors upon differentiation of tissues.

Throughout the foregoing I have spoken of the work only in its relation to morphogenesis, more particularly to the processes of embryonic development. There are others to follow me who are more competent to speak with authority upon the uses of the method in the study of regeneration, wound healing and tumor growth, as well as upon the physiology of the simple tissues. One thing I should, however, like to point out, and that is, that the few data we now have afford additional evidence of the underlying identity of the processes which are concerned in normal and abnormal development and in the maintenance function of cells.

The realization of much that has just been said will depend upon improvements in technique. In order to study the reactions of living cells and tissues we must be able not only to keep them alive but also to maintain them under satisfactory physiological conditions, as regards nutrition and respiration, for long periods of time. Much remains to be accomplished, but we may expect much from the efforts of workers already in the field, who have brought so much ingenuity to bear upon the difficulties involved in their work. 